\title{
Recent Advance in the Management of Dysplasia in the Ulcerative Colitis
}

\author{
Dong-Hoon Yang \\ Department of Gastroenterology, Asan Medical Center, University of Ulsan College of Medicine, Seoul, Korea
}

Received November 16, 2021

Accepted November 17, 2021

Corresponding author:

Dong-Hoon Yang

E-mail: dhyang@amc.seoul.kr

https://orcid.org/0000-0001-7756-2704
In patients having long-standing ulcerative colitis (UC), the risk of colorectal cancer (CRC) increased compared with general population. Dysplasia is a precancerous lesion of colitic patients, and traditionally total proctocolectomy was considered as a standard therapy to prevent colorectal cancer in UC patients. However, even with ileal pouch-anal anastomosis (IPAA), patients who underwent total proctocolectomy may experience early and late postoperative complications, such as ileus, bleeding, pouchitis, and so on. In addition, the bowel movement after proctocolectomy with IPAA reaches a median of seven times per day, and a considerable proportion of patients require daytime and nighttime pads. Change in the strategy for managing dysplasia started from two early studies, which suggested polypectomy for polypoid dysplasia to prevent CRC in colitic patients. After that, many studies supported that polypectomy should be the first option for the management of polypoid dysplasia. Moreover, recent studies suggested the feasibility of endoscopic submucosal dissection as a therapeutic option for nonpolypoid dysplasia, although long term, large studies should be followed.

Key Words: Ulcerative colitis; Colorectal cancer; Dysplasia; Polypectomy; Proctocolectomy

\section{INTRODUCTION}

Patients having long-standing ulcerative colitis (UC) and Crohn's colitis are exposed to the increased risk of colorectal cancer (CRC) [1-3]. Dysplasia, a precancerous lesion of CRC in the patients having long-standing inflammatory bowel disease (IBD), can be categorized into indefinite for dysplasia (IND), low-grade dysplasia (LGD), and high-grade dysplasia (HGD) [4]. Traditionally, total proctocolectomy had been regarded as a standard treatment not only for CRC but also for dysplasia in UC patients [4]. However, since early studies about the feasibility of polypectomy for dysplasia $[5,6]$, subsequent studies have supported endoscopic resection of polypoid dysplasia could be the first choice for the prevention of CRC in IBD, mostly UC patients. The pooled incidence of CRC after endoscopic resection of polypoid dysplasia is 5.3 cases per 1,000 patient-years in the colitic patients [7], and the incidence of post-colonoscopy CRC was
2 cases per 1,000 patient-years according to a recent metaanalysis regarding outcomes after endoscopic resection of dysplasia in colitic patients [8]. Therefore, recent guidelines suggest that endoscopic resection as a key modality for the treatment of visible and endoscopically resectable dysplasia in the colitic patients [9-11].

\section{HISTOLOGIC FEATURES OF DYSPLASIA IN UC}

By definition, dysplasia is histologically unequivocal neoplastic epithelium without evidence of tissue invasion and can be categorized as followings: negative for dysplasia, indefinite for dysplasia, and positive for dysplasia [12]. IND is applied to epithelial changes showing extraordinary regeneration but not sufficient for an unequivocal diagnosis of dysplasia. Positive for dysplasia can be subdivided into LGD and HGD. Colitis-associated dysplasia frequently shows his-

Copyright $($ Korean Society of Gastrointestinal Cancer Research.

(i) \$ This is an Open Access article distributed under the terms of the Creative Commons Attribution Non-Commercial License (http://creativecommons.org/licenses/ by-nc/4.0). which permits unrestricted non-commercial use, distribution, and reproduction in any medium, provided the original work is properly cited. 
tologic features different from sporadic dysplasia (adenoma) in the non-colitic segment or non-IBD patients $[13,14]$. Neoplastic glands of sporadic adenoma keep uniformity in the size and diameter and has similar configuration in a lesion $[13,14]$. Proportion of the stroma relative to neoplastic glands is low in a sporadic adenoma. On the other hand, colitis-associated dysplasia shows variety in the configuration, size, and diameter of neoplastic glands. The amount of stroma in the colitis-associated dysplasia is variable $[13,14]$. Typically, the proliferation zone of colitis-associated dysplasia is located at the base of glands unlike the sporadic adenomas of which proliferation zone starts at the apical part of the glands [14]. Sporadic adenoma is easily distinguishable from surrounding non-neoplastic mucosa, as it shows a sharp delineation. However, the delineation of colitisassociated dysplasia from surrounding mucosa is frequently irregular and often vague [14]. The indistinctness of borders between the colitis-associated dysplasia and the background mucosa hinders early detection of dysplasia under colonoscopy and makes endoscopic resection of dysplasia difficult or often impossible. Despite the difference in histologic features between colitis-associated and sporadic dysplasia, differentiating one from the other is challenging. Therefore, not only histologic features but also clinical data such as age, duration of disease, lesion location (beyond or within the coiltic segment), and endoscopic findings are taken together before making diagnosis.

\section{ENDOSCOPIC DESCRIPTION AND CLASSIFICATION OF DYSPLASIA}

Previous terms to describe dysplasia in IBD, including dysplasia-associated lesion or mass (DALM), adenoma-like lesion or mass (ALM), ALM-like DALM, and raised lesion with dysplasia (RLD), are confusing and not relevant to describe endoscopic characteristics [14]. In addition, the term, flat dysplasia, referred to lesions that were endoscopically undetectable according to the American Gastroenterological Association technical review published in 2010 [15]. However, this makes another confusion as the term, flat dysplasia, has also been used to indicate endoscopically detect- able dysplasia showing grossly 'flat' morphology. To solve these problems in the terminology for dysplasia detected at surveillance colonoscopy, the international consensus statement of the surveillance for colorectal endoscopic neoplasia detection and management in IBD patients (SCENIC) suggested a new endoscopic classification system for colitisassociated dysplasia [10]. According to the SCENIC classification, dysplasia should be divided into visible and invisible dysplasia. The term, flat dysplasia should not be used to indicate 'invisible' or 'endoscopically undetectable' dysplasia. Second, the previous imprecise terms, such as DALM, ALM, ALM-like DALM, and RLD, were abandoned. Instead, the Paris classification for sporadic colorectal neoplasia (CRN) was adopted to describe visible dysplasia and the presence of ulcerations and distinctness of borders should be described (Table 1).

\section{RISK OF CRC IN UC PATIENTS WITH DYSPLASIA}

According to the UC cohort of St Mark's Hospital, where started colonoscopic surveillance program in 1971, the risk of CRC was significantly higher in those with dysplasia than in those without dysplasia [16]. Kaplan-Meier analysis showed that 1-year- and 3-year-cumulative incidences of CRC in those with HGD were $41 \%$ and $54.3 \%$, respectively. Among patients with HGD who underwent immediate colectomy, 55.2\% already had CRC in their surgical specimens. The 1-year-, 3-year-, and 5-year-cumulative incidences of CRC in those with LGD were 9.9\%, 18.4\%, and $21.2 \%$. Among those who had LGD and underwent immediate colectomy, $28.1 \%$ had CRC in the surgical specimen. Hazard ratio of developing CRC for UC patients with dysplasia versus UC patients with neither dysplasia nor sporadic adenoma was 7.8 (95\% confidence interval [CI], 2.4-25.7; p < 0.001 ) for LGD and 33.1 (95\% CI, 9.7-112.9; $\mathrm{p}<0.001)$ for HGD. Among UC patients diagnosed with LGD, those with non-polypoid or endoscopically invisible LGD, LGD $\geq 1 \mathrm{~cm}$ in size, and LGD preceded by IND were more likely to progress HGD or CRC during a median 2 years of follow-up [17]. 
Table 1. Terminology to Describe Visible Dysplasia Detected by Colonoscopy in the Patients with Inflammatory Bowel Diseases

\begin{tabular}{ll}
\hline \multicolumn{1}{c}{ Terms } & \multicolumn{1}{c}{ Definition } \\
\hline $\begin{array}{l}\text { Adaption of Paris classification } \\
\text { Polypoid (0-I) } \\
\text { Pedunculated (0-Ip) }\end{array}$ & Lesion protruding from the mucosa into the lumen over or equal to $2.5 \mathrm{~mm}$ \\
Sessile (0-Is) & Lesion attached to the mucosa by a stalk \\
Non-polypoid (0-II) & Lesion not attached to the mucosa by a stake: entire base is contiguous with the mucosa \\
Superficial elevated (0-IIa) & Lesion with little $(<2.5 \mathrm{~mm}$ ) or no protrusion above the mucosa \\
& Lesion with protrusion but $<2.5 \mathrm{~mm}$ above the lumen (or less than the height of the closed \\
Flat (0-IIb) & cup of a biopsy forceps) \\
Depressed (0-IIc) & Lesion without protrusion above the mucosa \\
General descriptors & \\
Ulcerated & Ulceration (fibrinous-appearing base with depth) within the lesion \\
Border & Distinct: discrete and distinguishable from surrounding mucosa \\
& Indistinct: not discrete and not distinguishable from surrounding mucosa
\end{tabular}

Suggested by SCENIC consensus statement [10]. SCENIC, surveillance for colorectal endoscopic neoplasia detection and management in inflammatory bowel disease patients: international consensus recommendations.

\section{SURGICAL TREATMENT OF DYSPLASIA IN UC}

According to a study in the era of poor endoscopic images, 7 of 12 long-standing UC patients with endoscopically visible dysplasia, so-called DALM at that time, had CRC [18]. Therefore, proctocolectomy has been suggested as a therapeutic option for dysplasia in UC [12]. In a meta-analysis, the positive predictive value of LGD for concurrent CRC at colectomy was $25.5 \%$ and this supported proctocolectomy as a standard treatment of dysplasia in UC [19]. However, proctocolectomy carries high risk of post-operative complications [20]. Ileal pouch anal anastomosis (IPAA) provides chance to save the anus of the patients who underwent proctocolectomy $[21,22]$, and IPAA was possible $89 \%$ of UC patients in a Korean multicenter retrospective analysis [23]. However, proctocolectomy carries high risk of postoperative complications regardless of the preservation of anus. In the same Korean cohort, $34.7 \%$ of UC patients experienced postoperative complications. Ileus (5.1\%), bleeding (3.8\%), anastomotic leakage (3.6\%), intraabdominal abscess (1.9\%), and major wound dehiscence (1.4\%) comprised the early postoperative complications [23]. Late complications, such as pouchitis, fistula and anastomotic stricture occurred in $14 \%, 2.6 \%$, and $1.8 \%$ of patients who underwent proctocolectomy with IPAA, respectively [23]. A recent meta-analysis including 28 studies reporting outcomes from surgical treatment such as total or subtotal colectomy reported $9-65 \%$ of early complications and $17-55 \%$ of late complications [24]. Infectious complications and ileus were two most frequent early complications. The mean incidence of long-term complications, such as pouchitis, fecal incontinence, and small bowel obstruction was $29 \%, 21 \%$, and $17 \%$, respectively [24]. According to a large IPAA cohort study, colectomized UC patients with IPAA reported median 7 times of bowel movement per day at 1, 5, and 10 years after surgery and required daytime pads $19.3 \%$ at 1 year, $18.1 \%$ at 5 years, and $20.7 \%$ at 10 years after surgery [25]. The proportion of nighttime pad requirement was slightly higher than that of daytime pad requirement in that study [25]. So, patients should understand the possible long-term change in their bowel habit as a result of restorative proctocolectomy.

\section{CAN POLYPECTOMY REDUCE CRC IN UC PATIENTS?}

The paradigm shift from proctocolectomy to endoscopic treatment for dysplasia in UC started from two retrospective studies published in 1999 [5,6]. In one study including 24 UC patients with colitis-associated dysplasia, the recurrence 
rate of dysplasia was $4 \%$ during mean 3.5 years of followup period [6]. In the other study that included $48 \mathrm{UC}$ or Crohn's colitis patients who underwent endoscopic resection of dysplastic polyps, polyps recurred in $48 \%$ of patients during mean 4.1 years of follow-up period [5]. Nonetheless, no cancer developed in these two studies $[5,6]$. Since the earlier studies, many studies reported the outcomes of endoscopic resection of dysplasia, mostly showing polypoid morphology. A recent meta-analysis reported that the pooled risk of CRC and HGD after endoscopic resection of 1428 colonic lesions from 1037 IBD (including 933 UC) patients was 2 (95\% CI, 0-3) and 2 (95\% CI, 1-3) per 1,000 person-years, respectively. Although the postpolypectomy surveillance interval must be different from non-colitic population, this value is comparable to the incidence of post-colonoscopy CRC in non-colitic population (1.1-2.7 per 1,000 personyears) [26]. Therefore, endoscopic treatment for polypoid dysplasia can be accepted as a preventive intervention for CRC in patients with chronic colitis.

Unlike polypoid dysplasia, the outcomes of endoscopic treatment of non-polypoid dysplasia are not well investigated. The aforementioned long-term follow-up study for UC patients with LGD suggests non-polypoid morphology is associated with higher risk of progression to HGD or CRC, up to $65 \%$ at 5 years after diagnosis of LGD. Nonetheless, recent guidelines suggest surveillance rather than colectomy if a non-polypoid dysplasia was completely re- moved via endoscopic resection and no synchronous nonpolypoid dysplasia is present (Table 2) [11,27,28]. Recently, several small studies reported the outcomes of endoscopic resection of non-polypoid dysplasia which were removed by using endoscopic submucosal dissection (ESD) technique [29-34]. The median duration of follow-up in these studies is relatively short ranging from 21 to 37 months [29-33], except one study included 7 ESD cases of non-polypoid dysplasia of which median follow-up duration was 180 months (range, 105-271) [34]. In these studies, there was no CRC during the relative short follow-up and long-term outcome of endoscopic treatment for non-polypoid dysplasia should be investigated.

\section{ENDOSCOPIC RESECTION METHODS FOR DYSPLASIA IN UC}

Cold or hot snare polypectomy, endoscopic mucosal resection (EMR), and ESD are representative endoscopic resection techniques for the sporadic colorectal neoplasia and current guidelines for endoscopic resection of CRN recommend to select one of these techniques based on the gross morphology, size, and suspected submucosal invasion $[35,36]$. However, studies regarding the most appropriate resection techniques for dysplasia in UC are currently lacking and the current recommendation for choosing a certain endoscopic resection method for dysplasia is based on experts'

Table 2. Summary of Recent Guidelines for the Management of Visible Dysplasia in the Ulcerative Colitis or Crohn's Colitis [11,27,28]

\begin{tabular}{|c|c|c|}
\hline Group (yr) & Polypoid dysplasia & Non-polypoid dysplasia \\
\hline $\begin{array}{l}\text { ASGE } \\
(2015)\end{array}$ & $\begin{array}{l}\text { Patients with IBD whose polypoid dysplastic lesions } \\
\text { have been removed completely receive endoscopic } \\
\text { surveillance at } 1 \text { to } 6 \text { months and at } 12 \text { months, with } \\
\text { yearly surveillance thereafter }\end{array}$ & $\begin{array}{l}\text { Patients with IBD whose non-polypoid dysplastic lesions } \\
\text { have been removed completely receive endoscopic sur- } \\
\text { veillance at } 1 \text { to } 6 \text { months and at } 12 \text { months, with yearly } \\
\text { surveillance thereafter }\end{array}$ \\
\hline $\begin{array}{l}\text { ECCO } \\
(2017)\end{array}$ & $\begin{array}{l}\text { Polypoid dysplasia can be adequately treated by poly- } \\
\text { pectomy provided the lesion can be completely excised, } \\
\text { and there is no evidence of non-polypoid or invisible } \\
\text { dysplasia elsewhere in the colon }\end{array}$ & $\begin{array}{l}\text { Non-polypoid dysplastic lesions can be treated endosco- } \\
\text { pically in selected cases. If complete resection can be } \\
\text { achieved, with no evidence of non-polypoid or invisible } \\
\text { dysplasia elsewhere in the colon, continued surveillance } \\
\text { colonoscopy is reasonable }\end{array}$ \\
\hline $\begin{array}{l}\text { BSG } \\
(2019)\end{array}$ & $\begin{array}{l}\text { After complete removal of endoscopically resectable polypoid } \\
\text { dysplastic lesions, surveillance colonoscopy is recommen- } \\
\text { ded rather than colectomy }\end{array}$ & $\begin{array}{l}\text { After complete removal of endoscopically resectable non- } \\
\text { polypoid dysplastic lesions, surveillance colonoscopy is } \\
\text { suggested rather than colectomy }\end{array}$ \\
\hline
\end{tabular}

ASGE, American Society of Gastrointestinal Endoscopy; BSG, British Society of Gastroenterology; ECCO, European Corhn's and Colitis Organisation; IBD, inflammatory bowel disease. 
opinions [11]. Because of submucosal fibrosis resulted from long-standing inflammation, colitis-associated dysplasia is difficult to remove in en bloc manner. According to a recent retrospective study from Japan [34], when removing $10 \mathrm{~mm}$ or larger superficial tumors in UC patients, ESD showed superior histologically complete resection rate to EMR. The histologic complete resection rate of non-polypoid tumors was also higher in the ESD group than the EMR group [34]. The techniques and equipment for ESD have been described in many publications [37-39], and basically techniques and principles of ESD for sporadic CRNs can also be applied for colitis-associated dysplasia [40]. Unlike sporadic CRN, the surrounding mucosa of colitis-associated dysplasia frequently shows chronic inflammatory or scar changes [32], and the endoscopists may be confused with true dysplasia from surrounding non-dysplastic mucosa. Therefore, if a dysplasia is distinguishable from surrounding mucosa but relatively indistinct, diathermic marks are useful during ESD [40]. In addition to relative indistinctness of lesion borders, submucosal fibrosis is a common hurdle for successful ESD in colitis-associated dysplasia. The frequency of submucosal fibrosis ranged $66 \%$ to $100 \%$ according to several small ESD studies for UC or IBD patients [29-34]. Despite these challenges, en bloc resection and histologic complete resection rates of ESD for colitis-associated dysplasia ranged $80 \%$ to $100 \%$ and $67 \%$ to $97 \%$, respectively in these studies. However, these studies were performed by highly experienced therapeutic endoscopists who had expertise in ESD. Recently, a traction method for colorectal ESD has been suggested as a useful technique to achieve competent outcomes of ESD for sporadic CRNs even in the less experienced therapeutic endoscopists [41]. The role of traction methods to facilitate challenging ESD for colitis-associated dysplasia should be investigated in the future.

\section{CONCLUSION}

With advance in the endoscopic imaging technology and endoscopic resection techniques, endoscopic treatment for polypoid dysplasia became possible. Cumulated evidence for the polypoid dysplasia supports endoscopic resection as the first choice of management of polypoid dysplasia if it is endoscopically resectable. Although evidence is lacking, current guidelines expand the endoscopic resection as an option of management for non-polypoid dysplasia. Whether a dysplasia is polypoid or not, surveillance colonoscopy should be performed after endoscopically complete resection. However, if any synchronous, untreated colitisassociated dysplasia is present, colectomy should be the first choice of management for dysplasia in UC.

\section{CONFLICTS OF INTEREST}

No potential conflict of interest relevant to this article was reported.

\section{REFERENCES}

1. Jess T, Rungoe C, Peyrin-Biroulet L. Risk of colorectal cancer in patients with ulcerative colitis: a meta-analysis of population-based cohort studies. Clin Gastroenterol Hepatol 2012;10:639-645.

2. Colman RJ, Rubin DT. Histological inflammation increases the risk of colorectal neoplasia in ulcerative colitis: a systematic review. Intest Res 2016;14:202-210.

3. Zhiqin W, Palaniappan S, Raja Ali RA. Inflammatory bowel disease-related colorectal cancer in the Asia-Pacific region: past, present, and future. Intest Res 2014;12: 194-204.

4. Velayos F, Kathpalia P, Finlayson E. Changing paradigms in detection of dysplasia and management of patients with inflammatory bowel disease: is colectomy still necessary? Gastroenterology 2017;152:440-450.e1.

5. Rubin PH, Friedman S, Harpaz N, et al. Colonoscopic polypectomy in chronic colitis: conservative management after endoscopic resection of dysplastic polyps. Gastroenterology 1999;117:1295-1300.

6. Engelsgjerd M, Farraye FA, Odze RD. Polypectomy may be adequate treatment for adenoma-like dysplastic lesions in chronic ulcerative colitis. Gastroenterology 1999;117: 1288-1294; discussion 1488-1491.

7. Wanders LK, Dekker E, Pullens B, Bassett P, Travis SP, 
East JE. Cancer risk after resection of polypoid dysplasia in patients with longstanding ulcerative colitis: a metaanalysis. Clin Gastroenterol Hepatol 2014;12:756-764.

8. Mohan BP, Khan SR, Chandan S, et al. Endoscopic resection of colon dysplasia in patients with inflammatory bowel disease: a systematic review and meta-analysis. Gastrointest Endosc 2021;93:59-67.e10.

9. Annese V, Daperno M, Rutter MD, et al. European evidence based consensus for endoscopy in inflammatory bowel disease. J Crohns Colitis 2013;7:982-1018.

10. Laine L, Kaltenbach T, Barkun A, McQuaid KR, Subramanian V, Soetikno R. SCENIC international consensus statement on surveillance and management of dysplasia in inflammatory bowel disease. Gastroenterology 2015; 148:639-651.e28.

11. American Society for Gastrointestinal Endoscopy Standards of Practice Committee, Shergill AK, Lightdale JR, et al. The role of endoscopy in inflammatory bowel disease. Gastrointest Endosc 2015;81:1101-1121.e1-e13.

12. Riddell RH, Goldman H, Ransohoff DF, et al. Dysplasia in inflammatory bowel disease: standardized classification with provisional clinical applications. Hum Pathol 1983;14:931-968.

13. Langner C, Magro F, Driessen A, et al. The histopathological approach to inflammatory bowel disease: a practice guide. Virchows Arch 2014;464:511-527.

14. Vieth M, Neumann H. Current issues in inflammatory bowel disease neoplasia. Histopathology 2015;66:37-48.

15. Farraye FA, Odze RD, Eaden J, Itzkowitz SH. AGA technical review on the diagnosis and management of colorectal neoplasia in inflammatory bowel disease. Gastroenterology 2010;138:746-774, 774.e1-e4; quiz e12e13.

16. Choi CH, Rutter MD, Askari A, et al. Forty-year analysis of colonoscopic surveillance program for neoplasia in ulcerative colitis: an updated overview. Am J Gastroenterol 2015;110:1022-1034.

17. Choi CH, Ignjatovic-Wilson A, Askari A, et al. Lowgrade dysplasia in ulcerative colitis: risk factors for developing high-grade dysplasia or colorectal cancer. Am J Gastroenterol 2015;110:1461-1471; quiz 1472.
18. Blackstone MO, Riddell RH, Rogers BH, Levin B. Dysplasia-associated lesion or mass (DALM) detected by colonoscopy in long-standing ulcerative colitis: an indication for colectomy. Gastroenterology 1981;80:366-374.

19. Thomas T, Abrams KA, Robinson RJ, Mayberry JF. Meta-analysis: cancer risk of low-grade dysplasia in chronic ulcerative colitis. Aliment Pharmacol Ther 2007;25:657668.

20. Akiyama S, Rai V, Rubin DT. Pouchitis in inflammatory bowel disease: a review of diagnosis, prognosis, and treatment. Intest Res 2021;19:1-11.

21. Emoto S, Hata K, Nozawa H, et al. Risk factors for non-reaching of ileal pouch to the anus in laparoscopic restorative proctocolectomy with handsewn anastomosis for ulcerative colitis. Intest Res 2021. doi: 10.5217/ ir.2020.00158. [Epub ahead of print]

22. Lin $\mathrm{CC}$, Wei SC, Lin BR, et al. A retrospective analysis of 20-year data of the surgical management of ulcerative colitis patients in Taiwan: a study of Taiwan Society of Inflammatory Bowel Disease. Intest Res 2016;14:248257.

23. Yoon YS, Cho YB, Park KJ, et al. Surgical outcomes of Korean ulcerative colitis patients with and without colitisassociated cancer. World J Gastroenterol 2015;21:35473553.

24. Peyrin-Biroulet L, Germain A, Patel AS, Lindsay JO. Systematic review: outcomes and post-operative complications following colectomy for ulcerative colitis. Aliment Pharmacol Ther 2016;44:807-816.

25. Fazio VW, Kiran RP, Remzi FH, et al. Ileal pouch anal anastomosis: analysis of outcome and quality of life in 3707 patients. Ann Surg 2013;257:679-685.

26. Lieberman DA, Rex DK, Winawer SJ, Giardiello FM, Johnson DA, Levin TR. Guidelines for colonoscopy surveillance after screening and polypectomy: a consensus update by the US Multi-Society Task Force on Colorectal Cancer. Gastroenterology 2012;143:844-857.

27. Lamb CA, Kennedy NA, Raine T, et al. British Society of Gastroenterology consensus guidelines on the management of inflammatory bowel disease in adults. Gut 2019; 68(Suppl 3):s1-s106. 
28. Magro F, Gionchetti P, Eliakim R, et al. Third European evidence-based consensus on diagnosis and management of ulcerative colitis. Part 1: definitions, diagnosis, extraintestinal manifestations, pregnancy, cancer surveillance, surgery, and ileo-anal pouch disorders. J Crohns Colitis 2017;11:649-670.

29. Iacopini F, Saito Y, Yamada M, et al. Curative endoscopic submucosal dissection of large nonpolypoid superficial neoplasms in ulcerative colitis (with videos). Gastrointest Endosc 2015;82:734-738.

30. Suzuki N, Toyonaga T, East JE. Endoscopic submucosal dissection of colitis-related dysplasia. Endoscopy 2017; 49:1237-1242.

31. Kinoshita S, Uraoka T, Nishizawa T, et al. The role of colorectal endoscopic submucosal dissection in patients with ulcerative colitis. Gastrointest Endosc 2018;87:10791084.

32. Yang DH, Kim J, Song EM, et al. Outcomes of ulcerative colitis-associated dysplasia patients referred for potential endoscopic submucosal dissection. J Gastroenterol Hepatol 2019;34:1581-1589.

33. Manta R, Zullo A, Telesca DA, et al. Endoscopic submucosal dissection for visible dysplasia treatment in ulcerative colitis patients: cases series and systematic review of literature. J Crohns Colitis 2021;15:165-168.

34. Nishio M, Hirasawa K, Ozeki Y, et al. An endoscopic treatment strategy for superficial tumors in patients with ulcerative colitis. J Gastroenterol Hepatol 2021;36:498-
506.

35. Ferlitsch M, Moss A, Hassan C, et al. Colorectal polypectomy and endoscopic mucosal resection (EMR): European Society of Gastrointestinal Endoscopy (ESGE) clinical guideline. Endoscopy 2017;49:270-297.

36. Kaltenbach T, Anderson JC, Burke CA, et al. Endoscopic removal of colorectal lesions-recommendations by the US multi-society task force on colorectal cancer. Gastrointest Endosc 2020;91:486-519.

37. Saito Y, Otake Y, Sakamoto T, et al. Indications for and technical aspects of colorectal endoscopic submucosal dissection. Gut Liver 2013;7:263-269.

38. Yang DH, Jeong GH, Song Y, et al. The feasibility of performing colorectal endoscopic submucosal dissection without previous experience in performing gastric endoscopic submucosal dissection. Dig Dis Sci 2015;60:34313441.

39. Toyonaga T, Nishino E, Man-I M, East JE, Azuma T. Principles of quality controlled endoscopic submucosal dissection with appropriate dissection level and high quality resected specimen. Clin Endosc 2012;45:362-374.

40. Yang DH, Rey I. Endoscopic submucosal dissection for colitis-associated dysplasia. Clin Endosc 2019;52:120128.

41. Bordillon P, Pioche M, Wallenhorst T, et al. Double-clip traction for colonic endoscopic submucosal dissection: a multicenter study of 599 consecutive cases (with video). Gastrointest Endosc 2021;94:333-343. 